\author{
Waheeb Ahmed \\ Research Scholar, Ph.D. in Information Technology On-going, Student \\ Kannur University, Kannur, India \\ Waheeb2003aden@yahoo.com \\ Babu Anto \\ Associate Professor, Ph.D. in Technology, Research Guide \\ Kannur University, Kannur, India \\ bantop@gmail.com
}

\title{
AN AUTOMATIC WEB-BASED QUESTION ANSWERING SYSTEM FOR E-LEARNING
}

\begin{abstract}
An automatic web based Question Answering (QA) system is a valuable tool for improving e-learning and education. Several approaches employ natural language processing technology to understand questions given in natural language text, which is incomplete and errorprone. In addition, instead of extracting exact answer, many approaches simply return hyperlinks to documents containing the answers, which is inconvenient for the students or learners. In this paper we develop technique to detect the type of a question, based on which the proper technique for extracting the answer is used. The system returns only blocks or phrases of data containing the answer rather than full documents. Therefore, we can highly improve the efficiency of Web QA systems for e-learning.
\end{abstract}

Keywords: Technology-Enhanced Learning; Question Answering Systems; e-Learning; Natural Language Processing; ICT in Education.

\section{INTRODUCTION}

The massive amount of unstructured and heterogeneous information on the Web makes it a valuable tool for e-learning. With the support of network and information technology, elearning has become a vital educational means.

The problem statement. Using search engines users can easily find potential answers to factual questions, which is a great help for improving the learning practice. However, the importance of using the Web for question answering (QA) is not fully utilized by search engines due to several reasons. First, most search engines use a keyword based query processing mechanism internally and are not designed for handling natural language questions. They return documents that are semantically similar to the original question, which is inappropriate as the student or learner expects to find the answer instead of similar documents to the question. Second, a search engine may return thousands of documents in response to a query. Users have to manually seek potentially relevant documents.

Additionally, e-learning questions are considered more complex questions as they require a source/domain knowledge and also long answers require to be extracted from multiple documents. Moreover these questions have inherent ambiguity. Therefore, the presence of unlimited document collections (for example, the web itself), coupled with improvements in Natural Language Processing (NLP) techniques and information retrieval (IR), has gained popularity for the development of a special class of QA.

As a solution to the problems mentioned above is to use a dedicated QA system that answers users' natural language questions. However, QA systems based on the web attempt to answer questions that require a fact, phrase, or one word answer. This is difficult for questions that are confined to a domain because the domain under consideration is unrestricted and no assumption can be judiciously made (Ajitkumar, Khillare, and Mahender, 2016). 
Classical architecture of QA system generally consists of three modules, question processing module, documents retrieval module, and answer processing module. Though QA systems give a better solution for enhancement of e-learning with the help of natural language processing (NLP) technology to understand students/learners' questions. For example, given the question: "What is the capital city of China?". When a question is received, the system performs classification task to determine the type of the question. That is, whether the question is asking about person, location, organization, etc. The system then constructs a query that is more appropriate to a search engine based on the question type. A second problem is that many approaches return a list of hyperlinks to potential answers without identifying the exact location of the answer, and they may be ineffective in finding answers from pages without keywords in queries while the students or learners are expecting short and concise answers to their questions. In our approach, we extract content blocks, phrases or single words for answers in relevant pages. The advantage of this approach is that even though some blocks do not contain the query keywords, they will still be extracted as answer block as long as they contain the answer and bear some similarity to other answer blocks. The blocks containing the answer are grouped into one page for easy comparison. By this way we can highly improve the effectiveness and efficiency of QA system for e-learning.

Analysis of recent studies and publications. Oleksandr and Marie (2011) proposed a system that answers natural language questions by using a repository of documents. A Web based QA system which is a popular one is Ask.com (Gruener, Warthen and Leeds, 1996), which returns a list of hyperlinks to potential answers for a given question. Our system generates extract answers as a result. Some QA systems relay on FAQ pages which play an important role for these QA systems. Jijkoun et. al (2005) utilized FAQ pages on the Web to handle Natural Language questions. Ramakrishnan et. al (2004) use a set of training questions and answers extracted either from FAQ on the Web or from other sources and used as a learning approach to look for answers to questions. Unfortunately, FAQ does not always conform/exist for different queries. Semi-structural information which contains a mix of structured and unstructured text in Web pages has also been used for QA. QuASM (Pinto et. al, 2002) generates specific answers to questions by using HTML tables. However, tables are not always available in Web pages. Lin et al (2003) and Cristina (2012) used a method to translate questions into object-property-value query database. The need for manual labeling is the biggest disadvantage of this approach. The main works of QA proposed by Berant (2013, 2014) which are based on knowledge base building introduce a method to construct the QA system based on semantic analysis. Comas(2012) and Bao(2014) proposed an approach of creating QA system based on the translation of question into answer based on knowledge base. Machine learning techniques are also adopted in many approaches for QA. Lin et al. (2003) provides a simple pattern for a question and employs pattern matching to find the answer. Clarke et al.(2001) uses redundant information to learn and extract required answer in a precise way as specified in Text Retrieval Conference(TREC). Singh and Dwivedi (2015) proposed an integrated method of pattern matching and machine learning to classify questions into predefined categories. A template mapping technique to identify the type of a Question is used, and based on which an query is sent for a specific search engine which was built for this purpose. The system extracts detailed content blocks from relevant pages as answers. However, concise answers are not generated by that system (Parthasarathy and Chen, 2007). Some of the methods and their effect for e-learning are proposed (Berezytskyi et. al, 2016) (Pinchuk, 2016) (Umryk, 2015) (Ivanytska et. al, 2015) ( Su et. al, 2005) (Shen, 2014) (Hsiao et. al, 2010) (McKimm et. al, 2003).

The article's goal. Traditional search engines (e.g. Google, Yahoo, Bing, etc) usually returns a list of hyperlinks as a response to a user's query and it is the responsibility of the user to open and read the documents referred by these hyperlinks to find the expected answer. 
Unlike these classical search engines, our QA system will return only exact and concise answers rather than hyperlinks to full documents. This paper proposes a learning support system to answer questions given in natural language aided by a set of Natural Language Processing technologies. The system is implemented to help school children and learners get information from the Web for their homework assignments. We have adopted eight question wh-words to be answered by the system, namely: what, which, when, where, who, how much, and how many to be answered by the system. This learning support system is able to analyze the learner's question, process the answer documents which are retrieved by the search engine, extract answer candidates from the document collection, generate a proper answer and present it to the learner. Such complex process is performed immediately by the QA system.

\section{RESEARCH METHODS}

The main goal of an e-learning support system is to provide accurate and immediate answers based on learners' provided question. Our proposed QA system architecture includes the following modules, namely: question analysis module and answer extraction module. The question processing module performs the following subtasks: question classification, question focus identification, query generation, question tokenization and stop-word removal. The answer extraction module performs a few subtasks, namely: document retrieval, passage retrieval and answer extraction/selection. The following sections present the functionality of every module.

\subsection{Question processing module}

This module performs a comprehensive analysis of the given question. The following sections explain the various subtasks performed by this module.

\subsubsection{Question tokenization}

This is a pre-processing step. The first task in question processing is to identify tokens, or those basic units which do not require to be subdivided in a subsequent processing. The given question will be split into individual words for further processing by the subsequent components.

\subsubsection{Stop words Removal}

Noise is generally defined in information retrieval as the insignificant, irrelevant words or stop words, which are normally coming in any natural language text. Stop words have an average availability in any standard language corpus and do not normally supply any information to classification tasks. These stop words have high frequencies of occurrences. These words are prepositions, conjunctions, article and interrogative words (Sinka, and Corne, 2003) ( Lo, He, and Ounis, 2005).

\subsubsection{Query generation}

Submitting questions to search engines may not produce desirable results due to the mismatching in between the natural language questions and the keyword based indexing and searching nature of search engines. Since most factoid questions come into a set of common "wh-words" questions, we can classify questions into different categories. Each category of questions has its possible answer format. Based on the category of a question and the possible answer format/structure, we can generate a more effective query. The query generation 
module converts the student/learner's question into a list of keywords (query) which is then forwarded to the retrieval engine for answer retrieval.

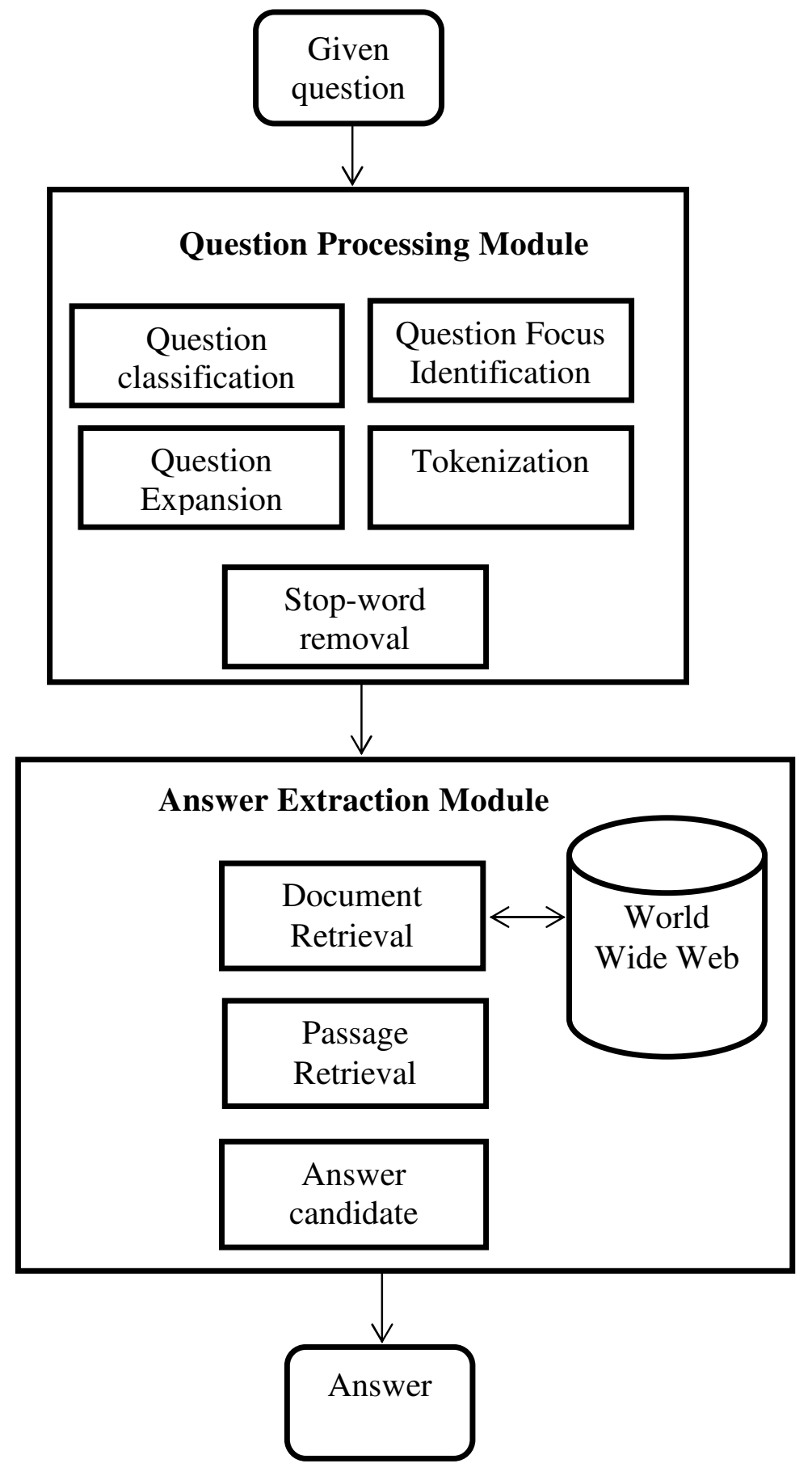

Figure 1. QA system architecture

\subsubsection{Question classification}

For the purpose of correctly answering a question, we usually need to understand what kind of information the question seeks, e.g., the sample question "who was the first person to travel in space?" asks for a person's name. Another example, when the system receives the 
following question, "where is the Eiffel tower located?" the system will classify the question as "LOCATION:city". This information helps the answer extraction module use the proper technique to extract only city name as an answer.

In this paper, we only consider the factual questions, who, what, where, when, how much and how many, i.e., TREC-style questions. The system uses a Support Vector Machine (SVM). SVM is a linear discriminate model which tries to find a hyper-plane with maximum margin for separating the classes. They are fast classifier for high dimensional data [333] to classify the questions. It is trained by about 1000 labelled questions, the question classification SVM can achieve above 80\% accuracy. Question taxonomy defines the semantic classes in which a question has to be put after classification. We followed the approach of two layered question taxonomy proposed by Li and Roth et al.(2002) of coarse and fine grained classes.

Features: SVM typically take as input a feature vector extracted from the question. The question is formulated as a vector of features and employed for training or test sample for learning. The mapping from a question to a class label is considered as a linear function defined over this feature vector. We extracted 7 features namely: Wh-word, head words or common noun, Head word's shape, position of main verb, class from primary method, unigram-trigram and related word.

\subsubsection{Question focus}

As a part of question processing, the question focus subtask tries to locate the question focus, which is defined as a noun or a noun phrase that is possibly to be available in the answer. For each submitted question, we will determine a focus, a focus head (the main noun) and the "modifiers" of the focus head (adjective, complement). Given the question: "who was the first person to travel in space?"

FOCUS = "first person to travel in space"

FOCUS-HEAD = "person"

MODIFIERS-FOCUS-HEAD = ADJ "first", COMP "person to travel in space"

The question focus is considered to have the following parts: (a) the focus head, (b) the modifiers list. The question processing module tries to identify the focus elements in the given question because this information will assist the answer extraction module in ranking the retrieved passages from the document collection.

\subsubsection{Query expansion}

After generation of the query from the question, we need to extend/expand the query through query expansion which improves the search process by adding semantically related terms and thus returns texts in which the query terms do not specifically appear(Jessie et. al, 2015). For example, in questions like, "Who invented the Piano?," another person may ask the same question as "Who devised the Piano?". The system should be able to understand that both of these questions share same meaning and thus the answer will be same for both questions. The system uses a popular thesaurus called WordNet to recognize semantically connected concepts. WordNet is a semantic structure containing words grouped into sets called synsets. Synsets are connected to each other by different relations such as synonyms, hyperonyms and meronyms.

\subsection{Answer extraction module}

This module is responsible of extraction and delivery of the final answer to the system user. It performs three subtasks, namely: document retrieval, passage retrieval and answer selection. The following sections explore these subtasks. 


\subsubsection{Document retrieval}

The search engine of our QA sends the queries obtained from the query generation stage to Google (Google, Online). The results returned from the search engine are preprocessed before being passed to the passage retrieval module.

\subsubsection{Passage retrieval}

Question answering performs the task of the extraction of relevant answers from sizeable documents, which is done by ordering the candidate passages retrieved by the passage retrieval module so that the most relevant ones are ranked first. Ordering of the passages is made in such a way that the passage which contains the question focus terms is ordered first. To perform this process, the web documents are split into passages to be ranked with the help of an n-gram score based on term frequency- inverse document frequency (tfidf). Passage retrieval module calculates n-gram similarity metric where the passages containing more question n-grams and longer ones are given higher score when comparing the candidate passages extracted from a set of documents using a keyword technique. The top 5 passages are returned as result.

\subsubsection{Answer selection and presentation}

The passages which are top-ranked are now returned (after weighting and ranking on basis of Similarity with question) as answer candidates. These passages undergo further processing to select those answer snippets that will be presented to the user. Some passages may be ranked higher just due to frequent occurrence of one of the main terms in the generated query. The system looks for the occurrence of noun phrases which are identified in the question focus section in the passages. To extract exact answers from the answer passages, it is necessary to find the section of the passage which is most similar to the question. Such section may consist of several sentences. We perform 2 steps to generate such part:

Step 1, compute the similarity between the question and each sentence in the passages.

Step 2, select the highest similar sentences according to the similarity distribution, which is answer generation.

Those snippets/sentences in which matches are found are ranked higher amongst the top ones. After similarity calculation, the system analyzes the answer snippets according to the classification done in question classification section. If the question was classified requiring any date or numerical expression then the system searches for these terms in the passages sentences (snippets) to match the answer type. The answer with the highest score is presented to the user. This helps the learner to quickly get the exact answer without the need to check many documents.

\subsection{Answer Corpus}

In order to prepare accurate and comprehensive answer, it is necessary to build an answer corpus categorized by different subjects. To avoid using a closed domain corpus as a source of knowledge for our QA system, we used open domain, that is the World Wide Web. This means the system can accept a given a question from any domain and use the web as the knowledge source for answers. The e-learning support system analyzes the question, automatically extract related text from the web, generate an exact answer and return it to learner.

\section{THE RESULTS AND DISCUSSION}

We selected four different types of answers to carry out the classification experiments. The answer type "NUMERIC" includes several subtypes namely: code, count, date, distance, 
money, order, period, percent, speed, temp, size, weight, other. The total testing data set consists of 450 questions of the four question types as shown in Table 1. These questions are submitted to the SVM classifier in different runs. The performance of the question classification task is shown in Table 2.

Table 1

Question set for each category

\begin{tabular}{|c|c|}
\hline Question Class & Number of questions \\
\hline PERSON & 110 \\
\hline LOCATION & 100 \\
\hline ORGANIZATION & 125 \\
\hline NUMERIC & 115 \\
\hline Total & 450 \\
\hline
\end{tabular}

Table 2 shows the performance of our answer type detection(question classification).

Table 2

Performance evaluation of the questions classifier

\begin{tabular}{|c|c|c|c|}
\hline Question Type & Precision (\%) & Recall (\%) & F-measure (\%) \\
\hline PERSON & 90.2 & 77.6 & 83.4 \\
\hline LOCATION & 83 & 66 & 73.5 \\
\hline ORGANIZATION & 87.1 & 71.2 & 78.4 \\
\hline NUMERIC & 79.7 & 85.8 & 82.6 \\
\hline AVERAGE & 85 & 75.2 & 80 \\
\hline
\end{tabular}

It is clear that our method works pretty well for the simple answer types such as person and number. And its performance on complex answer types is acceptable, also. The average score achieved for the classification task is $80 \%$.

For evaluating the answer extraction task, we adopted the same metric used by TRECQA Track for answer ranking. The adopted evaluation measure is called the Mean Reciprocal Rank (MRR). The score is computed as the rank position of the first correct answer. That is, If the first correct answer rank is $n$, the resulted score will be $1 / \mathrm{n}$. The testing set consists of 450 questions from TREC-QA Track (Table 1). The average recorded MRR score for the overall performance of our QA system is 0.523 which is a nice result comparing to other works on answer selection obtained in the literature of QA systems (Hovy et. al, 2001) (Ittycheriah et. al, 2001) (Soubbotin, 2001) (Grappy,2011) (Yen et. al,2013).

\section{CONCLUSIONS AND PROSPECTS FOR FURTHER RESEARCH}

In this paper, an approach for Web QA system is presented to improve e-learning. The QA system is proposed which aims to solve students/learners' questions to a great extent with minimal human-computer dialogue. It can be used to meet the requirements/needs of a more diverse student group. The system is completely automated to function in any subject domain. It answers students/learners' questions in the e-learning environment online and automatically. The system source of knowledge is the World Wide Web. A student/learner submits their question in natural language text and the proposed QA system responds with a concise answer from the web. It is really important to have such a system in e-learning environment. It is of benefit to both the instructor and the student. For the instructor, in the sense, he/she can be released from the heavy load of responding and answering students' 
questions and the students can find the answers to their questions without the limitation of time and space. The system is based on contextual search and adopts syntactic and semantic information. This leads to good accuracy in results. Our initial experiments are promising. Besides, the system can adapt to multiple resources as it is frequently available in e-learning domain. Additional effort is needed to improve the speed and the system's accuracy of prediction and to enable it to handle a very high workload.

\section{REFERENCES}

1. Ajitkumar,M. P., Khillare ,S. A., Mahender, C. N. 2016. Question Answering System, Approaches and Techniques: A Review. International Journal of Computer Applications, Vol. 141, No.3, 34-39.

2. Bao, J., Duan, N., Zhou, M., and Zhao, T. 2014. Knowledge-based question answering as machine translation. In: The 52nd Annual Meeting of the Association for Computational Linguistics, 1272-1294.

3. Berant, J., Chou, A., Roy, F., and Percy L. 2013. Semantic parsing on freebase from question-answer pairs. In: The 2013 Conference on Empirical Methods on Natural Language Processing, 153-1544.

4. Berant, J., Chou, A., Roy, F., and Percy L. 2014. Freebase QA: Information extraction or semantic parsing. In: The 2014 Conference on Empirical Methods on Natural Language Processing, 1511-1527.

5. Berezytskyi, M. M. , and Oleksyuk, V. P. 2016. Massive Open Online Cources as a Stage in the Development of E-Learning. In: Information Technologies and Learning Tools, 56(6):51-63.

6. Clarke, C. L. A., Cormack, G. V., and Lynam, T. R. 2001. Exploiting redundancy in question answering. In: Proceedings Of the 24th ACM SIGIR conference, 358-365.

7. Cristina, E.B., Pere, R., Comas. 2012. Full machine translation for factoid question answering. In: Proceedings of EACL, ACL , 20-29.

8. Google search engine.[Online]. Available at: http://www.google.com.

9. Grappy, A. , Grau, B., Falco, M-H. , Ligozat, A-L., Robba, I. , Vilnat., A. 2011.Selecting answers to questions from Web documents by a robust validation process", IEEE/WIC/ACM International Conferences on Web Intelligence and Intelligent Agent Technology, 55-62.

10. Gruener, G., Warthen, D., and Leeds, D. 1996. Ask. [Online]. Available at: http://www.ask.com.

11. Hovy, Hermjakob, E. U., Lin, C.Y. 2001. The use of external knowledge in factoid QA. In: Proceedings of the 10th Text Retrieval Conference, 644-652.

12. Hsiao, H-C , Chuang, C-F, Huang, T-C and Wu, C-F. 2010. Web-based Collaborative learning in secondary education: Teachers' reflection. In: International Journal of Cyber Society and Education, 3(1):15-36.

13. Ittycheriah, A. , Franz, M., Roukos, S. 2001. IBM's statistical question answering system TREC-10, in: Proceedings of the 10th Text Retrieval Conference, 258-264.

14. Ivanytska, N. , and Kern, M. 2015. Features of On-Line Learning in Austria. In: Information Technologies and Learning Tools, 46(2): 22-28.

15. Jessie ,O. , Xiuqin, M., Hongwu, Q. and Siau, C. L. 2015. A survey of query expansion, query suggestion and query refinement techniques. In: 4th International Conference on Software Engineering and Computer Systems (ICSECS), 112-117.

16. Jijkoun, V. , and Rijke, M. 2005. Retrieving Answers from Frequently Asked Questions Pages on the Web. In: Proeedings. Of CIKM 2005, pp. 76-83.

17. Kumar, P., Kashyap, S. , Mittal, A. ,and Gupta., S. 2005. A fully automatic question-answering system for intelligent search in e-learning documents. International Journal on E-Learning. 4.1 , 149(18).

18. Li , X. , and Roth, D. 2002. Learning Question Classifiers", Proceedings of the 19th International Conference on Computational Linguistics (COLING2002).

19. Lin, J. , and Katz, B. 2003. Question Answering from the Web Using Knowledge Annotation and Knowledge Mining Techniques. In: Proceedings of CIKM 2003, 116-123.

20. Lo, R. T.-W., He, B., and Ounis, I. 2005. Automatically building a stop-word list for an information retrieval system. In Journal on Digital Information Management: Special Issue on the 5th Dutch-Belgian Information Retrieval Workshop (DIR).

21. Magenta, S. T., Sepia, X., and Turquoise, U. 1995. Wombat genetics. In: Widiculous Wombats, Violet, Q., ed. New York: Columbia University Press. 123-145.

22. McKimm, J., Jollie, C. , and Cantillon, P. 2003. Web based learning. In: ABC of learning and teaching 326(7394): 870-873.

23. Oleksandr, K., and Marie, F. M. 2011. A Survey on Question Answering Technology from an Information Retrieval Perspective. In: Information Sciences, Vol. 181, 5412-5434. 
24. Parthasarathy, S. , and Chen, J. 2007.A Web-based Question Answering System for Effective e-Learning. In: Proceedings of the Seventh IEEE International Conference on Advanced Learning Technologies (ICALT 2007), 142 - 146.

25. Pinchuk, O. P. 2016. Perspective Analysis of Use of Social Networks as Learning Tools in Learning Environment. In: Information Technologies and Learning Tools, 54(4):83-98.

26. Pinto, D. , Croft, W. , Branstein, M. ,Coleman, R. , King, M., Li, W. , and Wei, X. 2002.Quasm: A system for question answering using semi-structured data. In: Proceedings of the Joint Conference on Digital Libraries (JCDL), pp. 46-55.

27. Ramakrishnan, G. , Chakrabarti, S. , Paranjpe, D. ,and Bhattacharyya, P. 2004. Is question answering an acquired skill?", In Proc. of WWW2004, 111 - 120.

28. Shen, Q. 2014. Web-based Autonomous Learning in the Chinese EFL Setting. In: Theory and Practice in Language Studies, 4(7):1409-1414.

29. Singh, V. , and Dwivedi, S. K. 2015. An Integrated Pattern Matching and Machine Learning Approach for Question Classification", In: Proceedings of the 1st International Conference on Next Generation Computing Technologies (NGCT-2015), 762-767.

30. Sinka, M. P. and Corne, D. W. 2003. Towards modernized and web-specific stoplists for web document analysis. In: Proceedings of te IEEE/WIC International Conference on Web Intelligence(WI 2003).

31. Soubbotin, M.M. 2001. Patterns of potential answer expressions as clues to the right answers. In: Proceedings of the 10th Text Retrieval Conference, 293-302.

32. Srihari, K., Li , W. , and Li , X. 2004. Information Extraction Supported Question- Answering. In: Advances in Open Domain Question Answering. Kluwer Academic Publishers.

33. Su, B. , Bonk, C. J. , Magjuka, R. J., Liu, X. , and Lee, S-H. 2005. Journal of Interactive Online Learning, 4(1):1-19.

34. Umryk, M. A. 2015. Organization of Distance Learning for Meeting the Needs of Modern Students. In: Information Technologies and Learning Tools, 45(1):146-155.

35. Yen, S-J., Wub, Y-C., Yang, J-C., Lee, Y-S., Lee, C-J., Liu, J-J. 2013.A support vector machine-based context-ranking model for question answering. Information Sciences, 77-87.

Text of the article was accepted by Editorial Team 29.01.2017

\title{
АВТОМАТИЗОВАНА СИСТЕМА ЗАПИТАННЯ / ВІДПОВІДЬ НА ВЕБ-ОСНОВІ ДЛЯ ЕЛЕКТРОННОГО НАВЧАННЯ
}

\author{
Ваід Ахмед \\ науковий співробітник, здобувач Ph.D. в галузі інформаційних технологій, студент \\ університет Каннур, Каннур, Індія \\ Waheeb2003aden@yahool.com
}

\section{Бабу Анто}

Ph.D. в галузі технологій, доцент, науковий керівник

університет Каннур, Каннур, Індія

bantop@gmail.com

\begin{abstract}
Анотація. Автоматична система Запитання / Відповідь (ПВ) на веб-основі є цінним інструментом для покращення електронного навчання й освіти. Існує кілька підходів, які використовують технологію обробки рідної мови, для того щоб зрозуміти запитання, наведені в тексті, але вони є неповними і припускаються помилок. Попри це, замість того, щоб виділити правильну відповідь, багато систем відсилають гіперпосиланнями до документів, у яких наведені відповіді. Такий підхід є незручним для студентів та учнів. У цій статті представлено розробку методики для визначення типу запитання, на основі якої використовується відповідна технологія для вилучення відповіді. Система повертає тільки блоки або фрази даних, що містять відповідь, а не повні тексти документів. Так ми можемо значно підвищити ефективність Web систем Запитання / Відповідь для електронного навчання.
\end{abstract}

Ключові слова: навчання 3 використанням технологій; системи запитання / відповідь; електронне навчання; обробка рідної мови; ІКТ в освіті. 


\title{
АВТОМАТИЗИРОВАННАЯ СИСТЕМА ВОПРОС / ОТВЕТ НА ВЕБ-ОСНОВЕ ДЛЯ ЭЛЕКТРОННОГО ОБУЧЕНИЯ
}

\section{Ваид Ахмед}

научный сотрудник, соискатель Ph.D. в области информационных технологий, студент университет Каннур, Каннур, Индия

Waheeb2003aden@yahool.com

\section{Бабу Анто}

Ph.D. в области технологий, доцент, научный руководитель университет Каннур, Каннур, Индия

bantop@gmail.com

\begin{abstract}
Аннотация. Система Вопрос / Ответ (ПВ) на веб-основе является ценным инструментом для улучшения электронного обучения и образования. Существует несколько подходов, которые используют технологию обработки родного языка, для того чтобы понять вопросы, приведенные в тексте, но они являются неполными и допускают ошибки. Кроме того, вместо того, чтобы выделить правильный ответ, многие системы отсылают гиперссылками к документам, в которых приведены ответы. Такой подход неудобен для учащихся. В этой статье представлена разработка методики для определения типа вопроса, на основе которой используется соответствующая технология для извлечения ответа. Система возвращает только блоки или фразы данных, содержащих ответ, а не полные тексты документов. Таким образом, мы можем значительно повысить эффективность Web систем Вопрос / Ответ для электронного обучения.
\end{abstract}

Ключевые слова: обучение с использованием технологий; системы вопрос / ответ; электронное обучение; обработка родного языка; ИКТ в образовании.

\section{(cc) BY-NC-SA}

This work is licensed under Creative Commons Attribution-NonCommercial-ShareAlike 4.0 International License. 